\title{
The Effect of Noise Meters Giving Visual and Auditory Alarms Used on Reducing Noise in Neonatal Intensive Care Unit
}

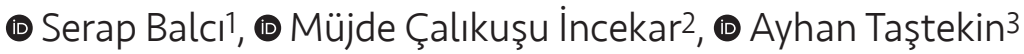 \\ 1istanbul University-Cerrahpaşa, Florence Nightingale Faculty of Nursing, Department of Pediatric Nursing, İstanbul, Turkey \\ 2Yüksek intisas University Faculty of Health Sciences, Department of Pediatric Nursing, Ankara, Turkey \\ 3istanbul Medipol University Faculty of Medicine, Department of Pediatrics, Division of Neonatology, İstanbul, Turkey
}

\begin{abstract}
Aim: This study was conducted to determine the effect of the use of a noise meter emitting visual and auditory alarms on reducing noise.

Materials and Methods: The study was conducted in an experimental design in a hospital in a Neonatal Intensive Care Unit (NICU). In the study, a noise meter emitting visual and auditory alarms and a digital noise meter were placed in a room (group 1); whereas, in the other room, only a digital noise meter was placed (group 2). The noise meter emitting visual and auditory alarms was hung on the most visible wall in the room and thus visual and auditory alarms were provided to the staff members in the room. The digital noise meter was hidden behind a closet in the same area in both rooms. The noise levels of the rooms were measured via the digital noise meter in both rooms in a way that data would come in continuously for two weeks.

Results: It was found that the total mean noise level in group 1 was significantly lower than group 2 for the two weeks $(p<0.01)$. It was determined that the noise levels on weekdays and at the weekend were significantly lower in group 1 than group 2 in week 1 ( $p<0.01$ ); whereas, in week 2 there was no difference between the groups in terms of the noise levels on weekdays and at the weekend ( $p>0.05)$.

Conclusion: The use of a noise meter emitting visual and auditory alarms might be effective in reducing noise in NICUs.

Keywords: Neonatal intensive care, newborn, noise, nursing, sound
\end{abstract}

\section{Introduction}

Individualized developmental care is an approach aiming at reducing the stress of newborns staying in neonatal intensive care units (NICUs) and offering relevant nursing interventions (1). In addition, it defines the physical, psychological, and emotional weaknesses of infants and their families and aims to minimize short-term and longterm possible complications associated with hospital experiences (2). The founder of modern nursing, Florence
Nightingale, formed the basis of developmental care with her words, "Nurses have responsibilities in creating and maintaining the environment which is a great help in the recovery process" (2). Physical, humanitarian, and system components forming the remedial environment are crucial to develop evidence-based applications for quality care $(3,4)$.

NICU nurses should be able to protect high-risk newborns from the sensorial stimuli which create toxic stress within the physical environment (3-5). In order to protect high-

\section{Address for Correspondence}

Müjde Çalıkuşu Incekar, Yüksek ihtisas University Faculty of Health Sciences, Department of Pediatric Nursing, Ankara, Turkey Phone: +90 5547860346 E-mail: mujdecalikusu@gmail.com ORCID: orcid.org/0000-0002-4472-2406

Received: 08.12.2020 Accepted: 20.04.2021

${ }^{(0)}$ Copyright 2021 by Ege University Faculty of Medicine, Department of Pediatrics and Ege Children's Foundation The Journal of Pediatric Research, published by Galenos Publishing House. 
risk newborns from noise in the sensorial environment, the ambient noise level in a NICU is recommended to be below 45 decibels $(\mathrm{dB})$ by the American Academy of Pediatrics (AAP) (6). However, in most studies, it was reported that the noise level was above $45 \mathrm{~dB}$ and often between 53-62 $\mathrm{dB}$ (7-10). In the study of Kol et al. (11), daytime noise levels were found to be higher in the NICU than at night.

Noise is a stressor for newborns. When a preterm newborn is exposed to noise in the NICU, it may give physiological and behavioural reactions depending on the increased stress. Studies report that preterm infants who are exposed to noise may develop problems such as a decrease in heart rate (12-14) and blood pressure in the cardiovascular system; a decrease in oxygen saturation $(12,13)$ and respiratory rate $(15)$ in the respiratory system; apnoea and a decrease in heart rate and brain perfusion depending on hypoxia $(15,16)$; sleep disorders $(13,17)$ and problems in long-term neurodevelopment; problems in language development (18) and hearing (19).

There are many ways to reduce noise. These methods include the use of sound-absorbing panels (20), ear plugs (18) and earmuffs (17), noise-reducing programs $(7,8,21$ $23)$, restructuring the unit structure $(24,25)$ and personnel behavioural change (8). In addition, it has been reported that the use of noise meters giving a visual alarm may also be effective in reducing noise (26-29). However, we did not find any study in the literature on noise meters emitting visual and auditory alarms. All of these above mentioned methods serve to reduce noise in a NICU. Since noise has many negative effects on the newborn, it is very important to protect them in the NICU from the noise of the environment. The purpose of this study was to determine the effect of the use of noise meters which emit visual and auditory alarms on noise reduction in a NICU.

\section{Materials and Methods}

\section{Design and Setting}

This study was conducted with an experimental design in a hospital in the NICU between December 2017 and January 2018. There were totally five rooms in the unit. The first and second rooms both had nine incubators and other devices such as ventilators, monitors and pumps and a sensor-fitted door according to the patient's condition. These two rooms were both $56 \mathrm{~m}^{2}$. The third room was a sepsis room with a total of eight sections and eight incubators. The fourth room was $66 \mathrm{~m}^{2}$ and had twelve incubators. The fifth room was a mother-infant adaptation room with four sections and eight incubators. The study was conducted in the first and second rooms of the unit as they had the same square meter.

Hypothesis: The noise meter emitting visual and auditory alarms used in NICU;

$\mathrm{H}_{0}$ : does not affect noise level.

$\mathrm{H}_{1}$ : reduces ambient noise level.

\section{Sample}

The population of this study consisted of all the staff members in the unit (doctors, nurses, secretaries, personnel and visitors). A total of 72 individuals (five doctors, 53 nurses, four secretaries, and 10 personnel) were working in the unit. They worked in shifts in the two rooms where the study was conducted.

\section{Measurements}

\section{Noise Meter Emitting a Visual and Auditory Alarm}

The device had an alarm system with three colours (red, yellow, and green) indicating the noise level. It could be regulated with a control button at $50 \mathrm{~dB}$ and $110 \mathrm{~dB}$ levels and at ten-decibel intervals. The device gave a green visual alarm between 50-60 dB and a yellow visual alarm between 60-70 dB. It gave a red visual and auditory alarm above 70 $\mathrm{dB}$ (Figure 1). The device emitted visual and auditory alarms and it was expected that the unit staff would change their behaviour in terms of reducing the noise due to these warnings.

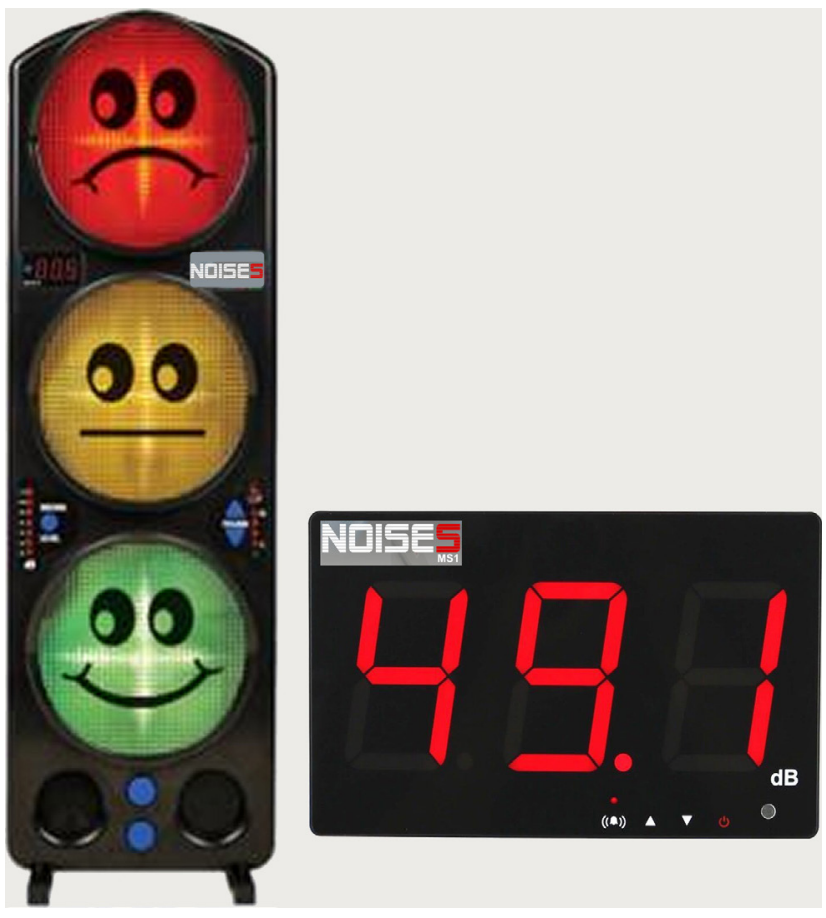

Figure 1. Noise meter which emits a visual and auditory alarm and a digital noise meter 


\section{Digital Noise Meter}

This device was set between 30-130 dB. The noise level was measured via the device in a way that data would be recorded every two seconds. The data in the device memory was transferred to a computer via a USB cable (Figure 1).

\section{Procedure}

In the study, a noise meter emitting visual and auditory alarms and a digital noise meter were placed in one room (group 1), whereas, in another room, only a digital noise meter was placed (group 2). At the beginning of this study, the staff members in the unit were informed about the study. The noise meter emitting visual and auditory alarms was hung on the most visible wall in the room and thus visual and auditory alarms were provided to the staff members in the room for two weeks. The digital noise meter was hidden behind a closet in the same area in both rooms. The noise levels of the rooms were measured via the digital noise meter in both rooms in a way that the data would be recorded continuously every two seconds for two weeks.

Ethics committee approval (date: 11/29/2017; No: 488) from İstanbul Medipol University Ethics Committee as well as institutional permission was obtained for this study.

\section{Data Analysis}

The results obtained in the study were assessed using the IBM SPSS Statistics 22 and R-3.5.2 program (30) for statistical analyses. Whether or not the variables were normally distributed was assessed via the KolmogorovSmirnov test. The paired sample t-test was used in assessing the data on weekdays and at the weekend and in the daytime and night. The student t-test was used in assessing the measurements in group 1 and group 2. Significance was assessed at a level of $p<0.05$.

\section{Results}

When examining the total noise level for two weeks, it was found that the mean noise level was significantly lower in group 1 than group $2(p<0.01)$ (Table I).

Table I. Evaluation of total noise measurements with noise meters giving visual and auditory alarms and digital noise meter

\begin{tabular}{|l|l|}
\hline Rooms & $\mathbf{M} \pm$ SD \\
\hline Group 1 & $69.92 \pm 1.41$ \\
\hline Group 2 & $70.38 \pm 1.43$ \\
\hline $\mathbf{t}$ & $\mathbf{- 3 , 1 4 4}$ \\
\hline $\mathbf{p}$ & $\mathbf{0 . 0 0 2}{ }^{* *}$ \\
\hline $\begin{array}{l}\text { t: Student-t test, }{ }^{* *} p<0.01 \\
\text { SD: Standard deviation }\end{array}$ & \\
\hline
\end{tabular}

When assessing the weekly noise for two weeks, it was determined that the noise levels on weekdays and at the weekend were significantly lower in group 1 than group 2 in week 1 ( $p<0.01$ ); whereas, in week 2 there was no difference between the groups in terms of the noise levels on weekdays and at the weekend ( $>>0.05)$ (Table II).

When comparing group 1 and group 2 within themselves; it was observed that in group 1 the noise level was significantly lower on weekdays and remained the same at the weekend in week 1, whereas in group 2 the noise level was significantly lower at the weekend and remained the same on weekdays in week 2 (Table II).

\section{Discussion}

Newborns are exposed to intense noise throughout their stay in NICUs. The major source of noise is reported to be human-made sounds (31,32). Newborns in NICUs get consistently exposed to sounds at a higher frequency than they would ever encounter in intrauterine life, which affects the nervous system development of preterm infants negatively (33). Studies report that noise may cause hearing impairment, sleep disorder, irritability (34), physiological imbalances in heart rate (12-14), respiratory rate (15), blood pressure (14) and oxygen saturation $(12,13)$, as well as irritation, agitation, crying, hypoxia and even minimal intracranial haemorrhage in newborns (35).

AAP has reported that noise levels in NICUs should be below $45 \mathrm{dBA}$ in the daytime and below $35 \mathrm{dBA}$ at night to provide a deep sleep, to assist the awake-asleep cycle and to protect newborns physiological stability $(6,36)$. However, in numerous studies, this limit was seen to be exceeded $(7-10,37)$. In the measurements conducted in the present study, it was found that while the lowest noise level was 68.01 $\pm 2.15 \mathrm{dBA}$, the highest noise level was $71.67 \pm 1.19 \mathrm{dBA}$ (Table I, II). According to this result, the noise levels determined in the NICU were higher compared to the recommendations of both the AAP (45 dB) and the Ministry of Health (averagely 50-55 dB per hour and $70 \mathrm{~dB}$ at maximum) $(6,38)$. This shows the necessity of increasing interventions aimed at reducing noise, inspecting the environment and staff continuously, and planning interventions aimed at reducing noise both at the institutional level and by healthcare professionals and to rigorously apply these interventions. Many measures can be taken to reduce noise. These measures may include applying "quiet time" throughout the shift $(26,31)$, reducing bedside visits, turning down the volume of monitors and alarms, taking phones out of the unit (39), speaking in a low voice (40), not dragging things in the unit, avoiding loud 
Table II. Evaluation of weekday and weekend noise measurements with noise meters giving visual and auditory alarms and digital noise meter

\begin{tabular}{|c|c|c|c|c|c|c|c|c|c|c|c|c|}
\hline & \multicolumn{4}{|l|}{ Group 1} & \multicolumn{4}{|l|}{ Group 2} & \multicolumn{2}{|c|}{$\begin{array}{l}\text { Weekday } \\
\text { (Group 1- } \\
\text { Group 2) }\end{array}$} & \multicolumn{2}{|c|}{$\begin{array}{l}\text { Weekend } \\
\text { (Group 1- Group } \\
\text { 2) }\end{array}$} \\
\hline & Weekday & Weekend & \multirow{2}{*}{$1 t$} & \multirow{2}{*}{ p-value } & Weekday & Weekend & \multirow{2}{*}{${ }^{1} \mathbf{t}$} & \multirow{2}{*}{ p-value } & \multirow{2}{*}{${ }^{2} t$} & \multirow{2}{*}{ p-value } & \multirow{2}{*}{${ }^{2} t$} & \multirow{2}{*}{$p$-value } \\
\hline & $M \pm S D$ & $M \pm S D$ & & & $M \pm S D$ & $M \pm S D$ & & & & & & \\
\hline Week 1 & $69.07 \pm 1.11$ & $69.46 \pm 2.40$ & -0.874 & 0.391 & $70.86 \pm 0.72$ & $71.36 \pm 1.05$ & $-2,093$ & $0.048^{*}$ & $-6,607$ & $0.001^{* *}$ & $-3,560$ & $0.001^{* *}$ \\
\hline Week 2 & $69.94 \pm 1.28$ & $70.43 \pm 1.03$ & $-1,451$ & 0.160 & $70.43 \pm 1.31$ & $70.07 \pm 0.86$ & 1,590 & 0.126 & $-1,321$ & 0.193 & 1,317 & 0.194 \\
\hline${ }^{1} t$ & $-2,941$ & $-1,830$ & & & 1,759 & 5,000 & & & & & & \\
\hline p & $0.007^{* *}$ & 0.080 & & & 0.092 & $0.001^{* *}$ & & & & & & \\
\hline
\end{tabular}

shoes (34), setting the ring tone of the phone to minimum (23) and using visual alarm systems (26-29).

In this study, a "noise meter emitting a visual and auditory alarm" was used to reduce the noise level. It is indicated that the most important property of these devices is that they are effective in reducing maximum noise levels. Reducing this condition which causes infants to experience sudden stress is an indicator of the effectiveness of these devices (29). Jousselme et al. (28) reported that the noise level was reduced to $2 \mathrm{~dB}$ as a result of using a noise meter emitting a visual alarm. It is recommended that noise meters emitting a visual alarm be used in NICUs, because they reduce noise levels by causing behavioural changes in healthcare professionals (27-29). In one study, it was reported that noise meters emitting a visual alarm reduced noise levels in the short term, but this decrease was not sustainable over one year even when a "quiet time" was added (26). Moreover, it has been emphasized that continuous education regarding the harmful effects of noise is very important for permanent noise reduction in NICUs. Also, this study assessed whether or not healthcare professionals were affected by these devices which emit visual and auditory alarms. Interventions were made to reduce noise and they reduced the ambient noise level.

The total noise level in the NICU over the two-week period was found to be significantly lower in group 1 than in group 2, which confirmed hypothesis 1 ( $p<0.05$; Table II). AAP (6) and White (41) state that the hourly noise level in NICUs should not exceed $45 \mathrm{dBA}$. In the Communiqué Regarding the Implementation Procedures and Principles of Intensive Care Services in Bedded Health Facilities in Turkey, it is reported that NICUs should not exceed $50-55 \mathrm{~dB}$ per hour on average and $70 \mathrm{~dB}$ at maximum (38). However, it was observed that the noise levels are not at the desire level either in this study or in other studies.
When comparing the weekly noise levels of the two groups on weekdays and at the weekend, it was found that noise levels were significantly lower in group 1 than group 2 in week 1 ; whereas, in week 2, there was no difference between the groups. The decrease in the noise levels in week 1 in group 1 did not continue in week 2, which was thought to be associated with intensity of work in the NICU and uncontrollable individual and environmental factors such as changes of healthcare professionals, the impact of visitors and the noise levels of materials used. In addition, it was noted that the noise level in the present study was higher than the level found by Jousselme et al. (28), which might be associated with the fact that besides a visual alarm, the noise meter used in this study emitted an auditory alarm when the sound exceeded $70 \mathrm{~dB}$. In addition, the first week may have caused a change in behaviour of the staff members due to the newness of the device in the unit, and in the second week, it was observed that there was no difference between the weekday and weekend noise levels in both groups, whereas it was expected that the noise level would decrease further in the second week. However, it was observed that there was no difference between the groups in terms of noise level in the $2^{\text {nd }}$ week. This situation may have developed due to uncontrollable environmental factors (alarm sounds, mobile phones, emergency interventions and so on), the intensity of the service and the carelessness of the staff members working in the shift. In this case, besides the devices we use to reduce noise, training staff members on this issue and using these devices together with different initiatives can increase effectiveness.

In other studies, "noise meters emitting only a visual alarm" can be compared with "noise meters emitting both a visual and an auditory alarm" and their effectiveness can be evaluated. 
It was seen that noise meters emitting a visual and auditory alarm are effective in reducing the ambient noise level; however, this decrease did not continue at the required level according to the levels specified. Therefore, it is crucial that instead of only one application, many applications should be conducted simultaneously in units to reduce noise and these applications should be converted into behavioural changes by healthcare professionals.

\section{Conclusion}

It was found that the total noise level in the NICU over a two-week period was significantly lower in group 1 than group 2.

According to these results, it can be suggested to;

Use a noise meter emitting a visual and auditory alarm in NICUs,

Measure noise regularly in NICUs in order to protect infants and staff members from possible problems caused by noise,

Create and apply regulations aimed at reducing noise in accordance with corporate standards.

\section{Acknowledgements}

The researchers thank the staff and families of the neonatal intensive care unit where the study was conducted. We thank Berkay Medical for the noise meter giving visual and auditory alarms and digital noise meters. This study was presented for poster presentation in $27^{\text {th }}$ National Neonatology Congress between 3-7 April 2019.

\section{Ethics}

Ethics Committee Approval: Ethics committee approval (date: 11/29/2017; no: 488) from İstanbul Medipol University Ethics Committee as well as institutional permission were obtained for the study.

Informed Consent: Informed consent was obtained.

Peer-review: Externally peer-reviewed.

\section{Authorship Contributions}

Surgical and Medical Practices: S.B., M.C.I., A.T., Concept: S.B., M.C.I., Design: S.B., M.C.I., Data Collection or Processing: S.B., M.C.I., A.T., Analysis or Interpretation: S.B., M.C.I., Literature Search: S.B., M.C.I., Writing: S.B., M.C.i.

Conflict of Interest: No conflict of interest was declared by the authors.

Financial Disclosure: The authors declared that this study received no financial support.

\section{References}

1. Symington A, Pinelli J. Developmental care for promoting developmental and preventing morbidity in preterm infants. Cochrane Database Syst Rev 2006; 19:CD001814.

2. Coughlin M, Gibbins S, Hoath S. Core measures for developmentally supportive care in neonatal intensive care units: theory, precedence and practice. I Adv Nurs 2009; 65:2239-48.

3. Akçay Didişen N. Travma bilgisi içeren yaşa uygun bakım. Içinde: Başbakkal, Z, Yardımcı, F, Akçay Didişen, N (editörler). Yenidoğan Yoğun Bakım Ünitelerinde Dönüşümsel Hemşirelik. Ankara, Nobel, 2016.

4. Coughlin M. Transformative Nursing in the NICU: Traumainformed Age-Appropriate Care. New York, Springer Publishing Company, 2014

5. Coughlin M. Trauma-informed, neuroprotective car efor hospitalised newborns and infants. Infant 2017; 13:176-9.

6. Noise: a hazard for the fetus and newborn. American Academy of Pediatrics. Committee on Environmental Health. Pediatrics 1997; 100:724-7.

7. Calikusu Incekar M, Balci S. The effect of training on noise reduction in neonatal intensive care units. I Spec Pediatr Nurs 2017; 22:1-8

8. Çalıkuşu İncekar $M$, Çeçen E, Balcı S, Mutlu B, Ulu Öğüt N, Hamilçıkan Ş. The effect of education in reducing noise on health personnels' knowledge level and behavioral change. I Turk Soc Intens Care 2019; 17:31-7.

9. Disher TC, Benoit B, Inglis D, et al. Striving for Optimum NoiseDecreasing Strategies in Critical Care: Initial Measurements and Observations. I Perinat Neonatal Nurs 2017; 31:58-66.

10. Gomes ELFD, Santos CMD, Santos ADCS, et al. Autonomic responses of premature newborns to body position and environmental noise in the neonatal intensive care unit. Rev Bras Ter Intensiva 2019; 31:296-302.

11. Kol E, Illaslan E, Ince S. Noise Sources and Levels in Intensive Care Units. J Turk Soc Intens Care 2015; 13:122-8.

12. Cardoso SM, Kozlowski Lde C, Lacerda AB, Marques JM, Ribas A. Newborn physiological responses to noise in the neonatal unit. Braz I Otorhinolaryngol 2015; 81:583-8.

13. Khalesi N, Khosravi N, Ranjbar A, Godarzi Z, Karimi A. The effectiveness of earmuffs on the physiologic and behavioral stability in preterm infants. Int I Pediatr Otorhinolaryngol 2017; 98:43-7.

14. Williams AL, Sanderson M, Lai D, Selwyn B), Lasky RE. Intensive care noise and mean arterial blood pressure in extremely lowbirth-weight neonates. Am J Perinatol 2009; 26:323-9.

15. Long JG, Lucey JF, Philip AG. Noise and hypoxemia in the intensive care nursery. Pediatrics 1980; 65:143-5.

16. Perlman JM, Volpe JJ. Episodes of apnea and bradycardia in the preterm newborn: impact on cerebral circulation. Pediatrics 1985; 76:333-8.

17. Duran R, Ciftdemir NA, Ozbek UV, et al. The effects of noise reduction by earmuffs on the physiologic and behavioral responses in very low birth weight preterm infants. Int I Pediatr Otorhinolaryngol 2012; 76:1490-3. 
18. Abou Turk C, Williams AL, Lasky RE. A randomized clinical trial evaluating silicone earplugs for very low birth weight newborns in intensive care. I Perinatol 2009; 29:358-63.

19. Chang EF, Merzenich MM. Environmental noise retards auditory cortical development. Science 2003; 300:498-502.

20. Altuncu E, Akman I, Kulekci S, Akdas F, Bilgen H, Ozek E. Noise levels in neonatal intensive care unit and use of sound absorbing panel in the isolette. Int / Pediatr Otorhinolaryngol 2009; 73:951-3.

21. Wang D, Aubertin C, Barrowman N, Moreau K, Dunn S, Harrold J. Examining the effects of a targeted noise reduction program in a neonatal intensive care unit. Arch Dis Child Fetal Neonatal Ed 2014; 99:F203-8.

22. Bayar Şakın N, Altundağ S. The effect of noise control training given to newborn neonatal intensive care unit workers and parents. Journal of Ankara Health Sciences 2020; 9:40-52.

23. Ramesh A, Suman Rao PN, Sandeep G, Nagapoornima $M$, Srilakshmi V, Swarnarekha M. Efficacy of a low cost protocol in reducing noise levels in the neonatal intensive care unit. Indian J Pediatr 2009; 76:475-8.

24. Liu WF. Comparing sound measurements in the single-family room with open-unit design neonatal intensive care unit: the impact of equipment noise. I Perinatol 2012; 32:368-73.

25. Krueger C, Schue S, Parker L. Neonatal intensive care unit sound levels before and after structural reconstruction. MCN Am J Matern Child Nurs 2007; 32:358-62.

26. Casey L, Fucile S, Flavin M, Dow K. A two-pronged approach to reduce noise levels in the neonatal intensive care unit. Early Hum Dev 2020; 146:105073.

27. Wang D, Aubertin C, Barrowman N, Moreau K, Dunn S, Harrold J. Reduction of noise in the neonatal intensive care unit using sound-activated noise meters. Arch Dis Child Fetal Neonatal Ed 2014; 99:F515-6.

28. Jousselme $C$, Vialet $R$, Jouve $E$, Lagier P, Martin C, Michel F. Efficacy and mode of action of a noise-sensor light alarm to decrease noise in the pediatric intensive care unit: a prospective, randomized study. Pediatr Crit Care Med 2011; 12:e69-72. doi: 10.1097/PCC.0b013e3181e89d91.

29. Chang YJ, Pan YJ, Lin YJ, Chang YZ, Lin CH. A noise-sensor light alarm reduces noise in the newborn intensive care unit. Am J Perinatol 2006; 23:265-71.
30. R Core Team. R: A language and environment for statistical computing. R Foundation for Statistical Computing, Vienna, Austria 2018. Available from: https://www.R-project.org/

31. Nathan LM, Tuomi SK, Müller AM, Kirsten GF. Noise levels in a neonatal intensive care unit in the Cape Metropole. S Afri I Child Health 2008; 2:50-54.

32. Joseph A, Ulrich R. Sound control for improved outcomes in healthcare settings. The Center for Health Care Design 2007; 4:1-15.

33. Aita M, Johnston C, Goulet C, Oberlander TF, Snider L. Intervention minimizing preterm infants' exposure to NICU light and noise. Clin Nurs Res 2013; 22:337-58.

34. Weich TM, Ourique AC, Tochetto TM, Franceschi CM. Effectiveness of a noise control program in a neonatal intensive care unit. Rev Bras Ter Intensiva 2011; 23:327-34.

35. Wachman EM, Lahav A. The effects of noise on preterm infants in the NICU. Arch Dis Child Fetal Neonatal Ed 2011; 96:F305-9. doi: 10.1136/adc.2009.182014.

36. Environmental Protection Agency. Office of Noise Abatement and Control. Information on Levels of Environmental Noise Requisite to Protect Public Health and Welfare With an Adequate Margin of Safety (Report No. 5509-74-004). Washington, DC, Government Printing Office, 1974.

37. Parra J, Suremain A, Berne Audeoud F, Ego A, Debillon T. Sound levels in a neonatal intensive care unit significantly exceeded recommendations, especially inside incubators. Acta Paediatr 2017; 106:1909-14

38. 2011 Yataklı Sağlık Tesislerinde Yoğun Bakım Hizmetlerinin Uygulama Usul ve Esasları Hakkında Tebliğde Değişiklik Yapılmasına Dair Tebliğ. Erişim tarihi: 11.08.2020. Erişim adresi: http://www.resmigazete.gov.tr/eskiler/2011/07/20110720-15. htm

39. Johnson AN. Adapting the neonatal intensive care environment to decrease noise. I Perinat Neonatal Nurs 2003; 17:280-8; quiz 289-90.

40. Chen HL, Chen $\mathrm{CH}$, Wu CC, Huang HJ, Wang TM, Hsu CC. The influence of neonatal intensive care unit design on sound level. Pediatr Neonatol 2009; 50:270-4

41. White RD. Recommended standards for newborn ICU designStandard 22 and 27. Report of the Eighth Consensus Conference on Newborn ICU Design, Florida, 2012. 